\title{
Impact of COVID-19 pandemic on pre-existing shoulder problems: Is telerehabilitation a useful tool for physical therapy?
}

\author{
COVID-19 pandemisinin önceden var olan omuz problemlerine etkisi: \\ Telerehabilitasyon fizik tedavi için yararlı bir araç mıdır?
}

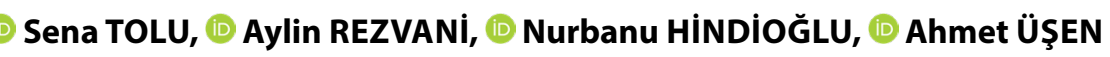

To the Editor,

On March 11, 2020, the world health organization announced coronavirus disease 2019 (COVID-19) outbreak as a pandemic. ${ }^{[1]}$ During this global crisis, worldwide governments set up severe rules limiting individual freedom and keeping social distancing to avoid the deterioration of national health-care systems. Patients who had specific life-threatening conditions or suffering from severe COVID-19 needing high-intensity levels of care (e.g., intensive care units) were permitted to refer to hospitals. Furthermore, physical therapy and rehabilitation programs were postponed to provide better care for inpatients with severe COVID-19. In an Italian survey, during the pandemic, more than $50 \%$ of stroke patients have reported a reduction in seeking treatment in the hospital, possibly in fear of being infected or being denied seeing their families after hospitalization. ${ }^{[2]}$ What can we say about the patients with painful musculoskeletal problems?

We analyzed the change in the rate of adhesive capsulitis (AC) after the Ministry of Health policies postponing physical therapy deemed not urgent to ensure safety. We collected data by reviewing computer records of patients dealing with shoulder problems who attended our physical medicine and rehabilitation outpatient clinic of Medipol University Hospital for the period from May 1, 2020, to July 1, 2020, and for the same period in 2019. The number of patients was 187 in 2019 and 103 in 2020, respectively. Interestingly, when the number of those with AC was 67 (35.82\%) in 2019, it was 70 (67.96\%) in 2020. There were no statistically significant differences in terms of age, gender, comorbidities, history of shoulder trauma/dislocation, and shoulder magnetic resonance imaging findings in patients between these 2 time intervals. Data showed that the ratio of patients presenting with $A C$ has been increased two-fold during the COVID-19 pandemic.

Some of the reasons for this increase might be related to the conversion of the majority of public hospitals to pandemic hospitals and the assignment of health professionals in COVID-19 clinics. Furthermore, hospital access to people with chronic musculoskeletal and neurologic diseases such as chronic low back pain, rotator cuff problems or stroke has been postponed. This strict decision was aimed at minimizing the possibility of contacting non-infected people with infected ones. Thus patients who may be living with pain and disability due to very painful musculoskeletal disorders were left untreated and this led to the progression of the disease.

Another reason could be that patients with just pain might have tried to cope with the problems by themselves at home rather than go to the hospital because of concerns about exposure to COVID-19. For reducing pain, patients generally take painkillers, apply cold or heat and massage and completely

Department of Physical Medicine and Rehabilitation, İstanbul Medipol University Faculty of Medicine, İstanbul, Türkiye

Submitted: 26.01.2021 Accepted after revision: 27.02.2021 Available online date: 02.03.2021

Correspondence: Dr. Sena Tolu. İstanbul Medipol Üniversitesi Tıp Fakültesi, Fiziksel Tıp ve Rehabilitasyon Anabilim Dalı, İstanbul, Türkiye.

Phone: +90 - 505 - 4424722 e-mail: dr.sena2005@gmail.com

๑) 2022 Turkish Society of Algology 
immobilize their shoulders for fear of harm which makes the situation even more complicated because they realize the limited shoulder range of motion until it affects their daily living activities.

The previous studies have evaluated the efficacy, validity, intrarater, and interrater reliability of telerehabilitation for both peripheral joints and spine disorders. A good to excellent results had been found for the different clinical outcomes such as pain, active, and passive range of motion, swelling, muscle strength, balance, and gait. ${ }^{[3]}$

During the COVID-19 pandemic, so many organizations such as the American Physical Therapy Association and the Italian Physiotherapy Association advised implementing telerehabilitation to physical therapy and rehabilitation processes. ${ }^{[4,5]}$

Telerehabilitation reduces the costs and saves time for both health care services and patients compared with traditional rehabilitation. Furthermore, patients can reach physical therapists in their home environment without the risk of contamination with COVID-19. After performing patient's physical assessments, physiatrists can plan a therapeutic exercise program, monitor their progress, and provide them continuous feedback. For the pandemic, it seems to be a suitable method for a face-to-face interview with a doctor, being examined and receiving treatment without needing to protect the social distancing and use a mask.

On the other hand, telerehabilitation may pose a problem for accurate diagnosis and treatment, as there is no possibility to use palpation and other special tests for diagnosis during a clinical examination. Also in cases with complex clinical findings and histories, making an online diagnosis and preparing a physical therapy program can be difficult and risky.

Is telerehabilitation a useful tool for physical therapy during the COVID-19 pandemic? We think that telerehabilitation may be a useful tool for patients with musculoskeletal problems to get an early diagnosis, treatment and regular follow-up. Thus, patients could be protected from hospital infections and health centers could get rid of unnecessary density and musculoskeletal problems are treated before they become chronic.

\section{References}

1. WHO. Coronavirus disease (Covid-19) pandemic. Available at: https://www.who.int/emergencies/diseases/novelcoronavirus-2019. Accessed Jul 2, 2020.

2. Morelli N, Rota E, Terracciano C, Immovilli P, Spallazzi M, Colombi $\mathrm{D}$, et al. The baffling case of ischemic stroke disappearance from the casualty department in the COVID-19 Era. Eur Neurol 2020;83:213-5.[CrossRef]

3. Mani S, Sharma S, Omar B, Paungmali A, Joseph L. Validity and reliability of Internet-based physiotherapy assessment for musculoskeletal disorders: A systematic review. J Telemed Telecare 2017;23:379-91. [CrossRef]

4. American Physical Therapy Association. Digital telehealth practice - connect for best practice, compliance, and health care. 2020. Available at: https://learningcenter.apta. org/ student/mycourse.aspx?id=f4259a2e-9c55-485ca353-079e073 de74d. Accessed Apr 23, 2020.

5. Associazione Italiana Fisioterapisti Italiani. Suggerimenti operativi per la teleriabilitazione. 2020. Available at: https://aifi.net/ suggerimenti-operativi-per-la-teleriabilitazione/. Accessed Apr 23, 2020. 